
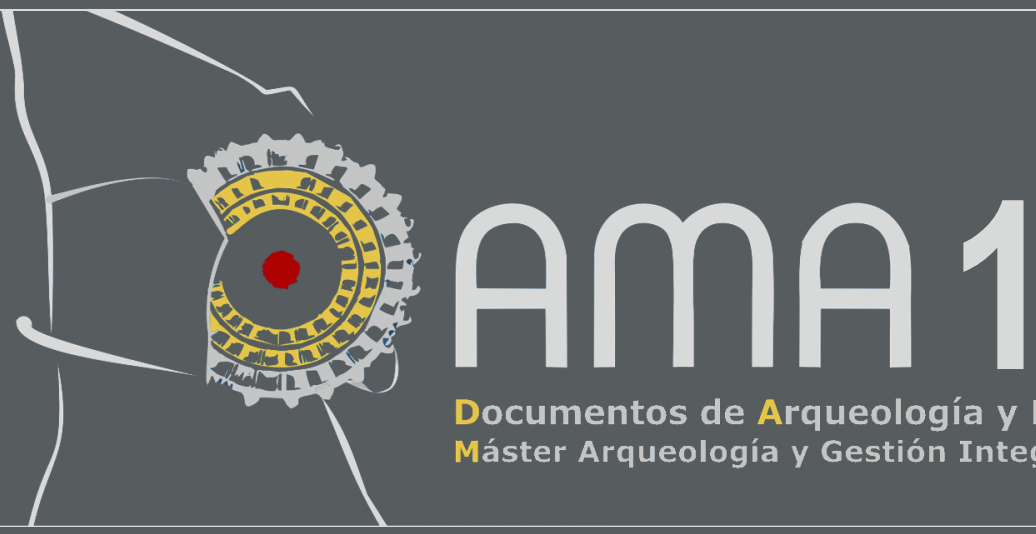

Documentos de Arqueología y Patrimonio Histórico

Máster Arqueología y Gestión Integral del Patrimonio de la Universidad de Alicante

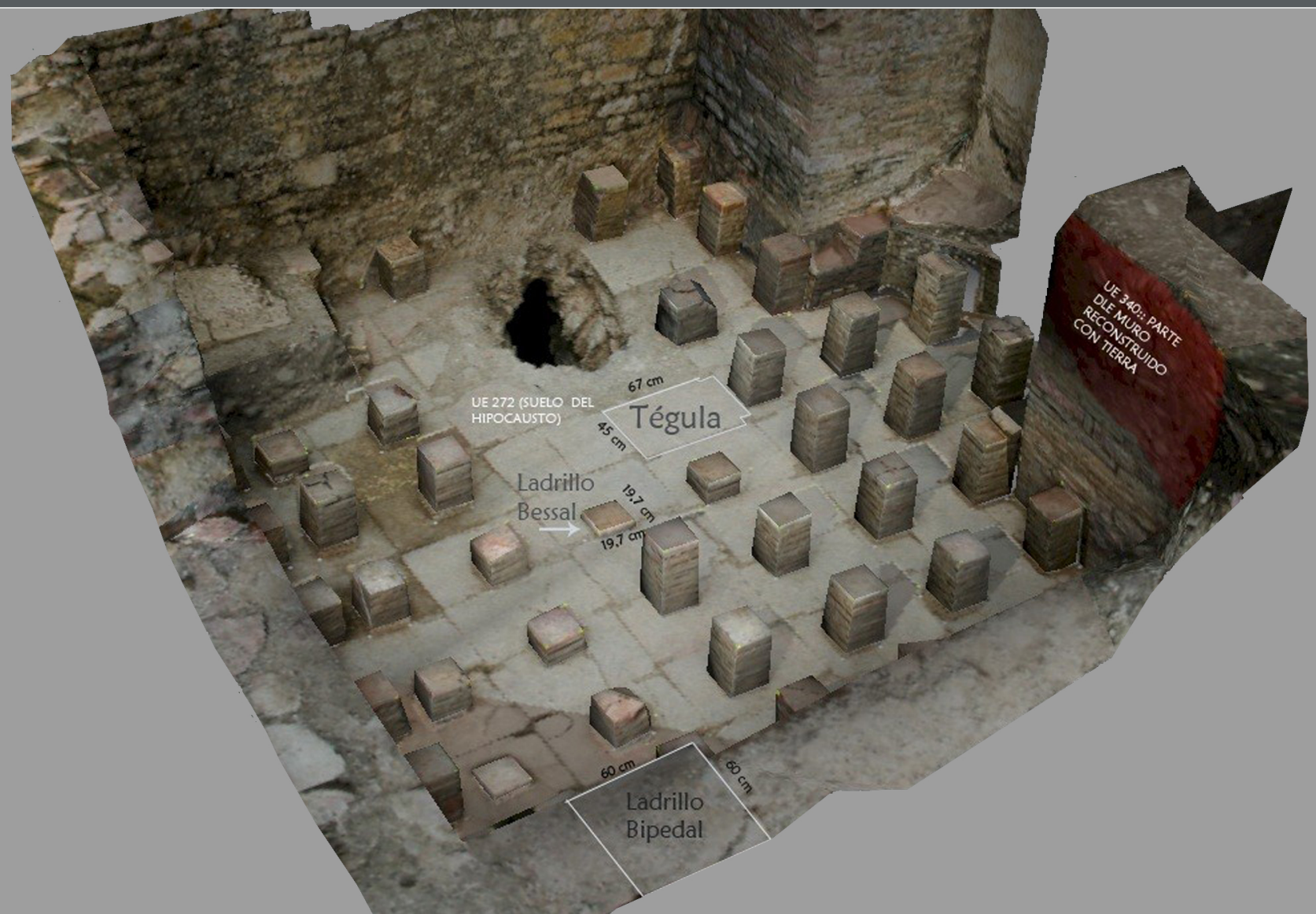

Documentos de Arqueología y Patrimonio Histórico Revista del Máster Universitario en Arqueología Profesional y Gestión integral del Patrimonio 



\section{DAMA 1}

\section{6}

DOCUMENTOS DE ARQUEOLOGÍA Y PATRIMONIO HISTÓRICO DEL MÁSTER UNIVERSITARIO EN ARQUEOLOGÍA PROFESIONAL Y GESTIÓN INTEGRAL DEL PATRIMONIO DE LA UNIVERSIDAD DE ALICANTE 


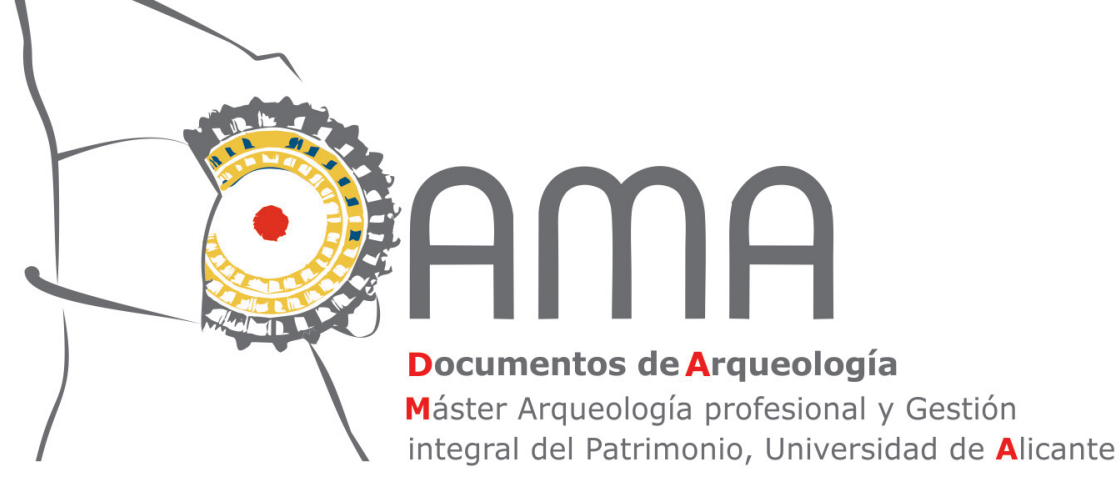

La revista electrónica DAMA. Documentos de Arqueología y Patrimonio Histórico surge como servicio para todos aquellos alumnos del Máster en Arqueología Profesional y Gestión Integral del Patrimonio de la Universidad de Alicante que se están iniciando en la investigación y cuya primera aportación a nuestra disciplina suele ser su Trabajo de Fin de Máster (TFM). Estos proyectos en muchos casos representan casi todo un curso de trabajo y esfuerzo, y con frecuencia quedan inéditos.

El objetivo de esta revista es ofrecer un medio que facilite la publicación de los resultados de sus TFM. La edición se presenta en versión digital y cuenta con su correspondiente ISSN. Se publica de forma anual en el sitio web de la Universidad de Alicante (http://web.ua.es/es/dama/) y en su repositorio (RUA). Los artículos publicados son descargables en formato PDF.

\section{Consejo de Redacción}

Directores (Coordinadores del Máster)

Carolina Doménech Belda

Fernando Prados Martínez

\section{Secretaria de Edición}

Julia Sarabia Bautista

\section{Vocales}

Los miembros de la Comisión Académica del Máster Universitario en Arqueología Profesional y Gestión del Patrimonio (http://dprha.ua.es/es/magip/comision-academica.html)

\section{Edita}

Máster Universitario en Arqueología Profesional y Gestión Integral del Patrimonio Departamento de Prehistoria, Arqueología, Historia Antigua, Filología Griega y Filología Latina

Facultad de Filosofía y Letras II

Universidad de Alicante

Ctra San Vicente del Raspeig s/n

E-03690 San Vicente del Raspeig (Alicante)

Web:http://dprha.ua.es

Teléfono: (+34) 965903663

Fax: (+34) 965903823

E-mail: revista.dama@ua.es

\section{ISSN}

$2530-2345$

\section{Portada}

Modelo fotogramétrico de un hypocaustum romano realizado por Ana Charquero 
EDITORIAL

Coordinación del máster

ENTREVISTA A SOLVEIG NORDSTRÖM: UNA MIRADA HACIA EL PASADO DE LA ESCUERA

Raúl Berenguer González ..

\section{ARQUEOLOGÍA Y MÉTODO}

EL ESTUDIO DE LOS MATERIALES CONSTRUCTIVOS DE TIERRA DEL CABEZO DEL POLOVAR (VILLENA, ALICANTE): APORTACIÓN A LAS FORMAS CONSTRUCTIVAS DE DOS PEQUEÑAS EDIFICACIONES CAMPESINAS DE LA EDAD DEL BRONCE EN EL LEVANTE PENINSULAR

María Pastor Quiles

VIVIENDAS POSTALAYÓTICAS: UNA APROXIMACIÓN A LOS ESPACIOS DOMÉSTICOS EN EL ARCHIPIÉLAGO BALEAR (550-123 ANE)

Octavio Torres Gomáriz

LAS FLOTAS DE GUARNICIÓN ROMANA EN LAS COSTAS DE HISPANIA A PARTIR DE LAS FUENTES EPIGRÁFICAS

Sergio Lledó Ramírez

UNA APROXIMACIÓN A LA RECONSTRUCCIÓN DEL PAISAJE HISTÓRICO: EL PROYECTO L'ALMISSERÀ Diana López Arroyo

NUEVAS PERSPECTIVAS PARA EL ESTUDIO ARQUEOLÓGICO DEL POBLAMIENTO RURAL MEDIEVAL EN ASPE (ALICANTE): HUERTAS Y ALQUERÍAS JUNTO AL RÍO TARAFA

Felipe Mejías López

ARQUEOLOGÍA DE LAS GUERRAS CARLISTAS

Iván Roldán Vergarachea

LA CERÁMICA DE USO ARQUITECTÓNICO EN NOVELDA: LA AZULEJERÍA DE FINALES DEL SIGLO XIX Y PRINCIPIOS DEL XX

Natalia Sala Pérez

PRÁCTICA Y USOS DE LA FOTOGRAMETRÍA DIGITAL EN ARQUEOLOGÍA

Ana $M^{a}$ Charquero Ballester.

\section{GESTIÓN Y PUESTA EN VALOR DEL PATRIMONIO}

ARQUEÓLOGOS CON DISCAPACIDAD. ARQUEOLOGÍA INCLUSIVA

Ana Samaniego Espinosa

"LES COVES DELS PESCADORS DE EL CAMPELLO": PROPUESTA DE RECUPERACIÓN, PUESTA EN VALOR Y USO PÚBLICO DE UN PATRIMONIO OLVIDADO

Ana Isabel Castro Carbonell .

LA COLONIA DE SANTA EULALIA. ESTUDIO Y PROPUESTA DE RECUPERACIÓN

Héctor de Arriba González

PROYECTO DE PUESTA EN VALOR DE LOS RESTOS DE LA GUERRA CIVIL EN LA CIUDAD DE ALICANTE

Leticia Victoria González Chouciño

ANTEPROYECTO MUSEOGRÁFICO DEL MUSEO DE HISTORIA DE SAX

Alberto Ochoa García

EL CONGRESO DE MÁSTER: UNA PROPUESTA DIDÁCTICA DEL MÁSTER DE ARQUEOLOGÍA DE LA UNIVERSIDAD DE ALICANTE

Ignasi Grau Mira, Sonia Gutiérrez Lloret, Carolina Doménech Belda, Julia Sarabia Bautista 



\section{Editorial}

La revista DAMA, Documentos de Arqueología y Patrimonio Histórico que sale ahora a la luz, surge en el marco del Máster en Arqueología Profesional y Gestión Integral del Patrimonio de la Universidad de Alicante con un doble objetivo. Por una parte, pretende ser una herramienta de divulgación de los trabajos de investigación que nuestros estudiantes realizan como proyecto fin de máster. Por otra, nace con el fin de ofrecer a los alumnos un medio que facilite la publicación de los resultados de su actividad investigadora.

Muchos han sido los trabajos de final de máster realizados desde que éste se implantara hace ahora diez cursos, abordando temáticas de diferentes orientaciones y periodos históricos, desde perspectivas que van desde lo exclusivamente arqueológico a otras más vinculadas con la gestión patrimonial. De ellos, algunos ya han sido publicados en diferentes medios, pero otros han quedado inéditos por distintos motivos. Con esta nueva revista que ahora comienza su andadura, ponemos a disposición de los estudiantes un espacio donde hacer visible el fruto de la tarea investigadora desarrollada a lo largo del curso. Por ello, la revista se proyecta con una periodicidad anual, donde cada número estará abierto al alumnado del curso académico correspondiente.

No obstante, no queremos olvidar el tiempo transcurrido hasta hoy. Por ello, este primer número está destinado a los alumnos que cursaron el máster en los años precedentes. En él, se publica una selección de trabajos realizados a lo largo de estos años. Este primer número de DAMA arranca con la entrevista a la veterana arqueóloga Solveig Nordström, cuya actividad en tierras alicantinas forma parte ineludible de la historia de la disciplina en estas tierras. Dicha entrevista fue realizada a propósito de un trabajo fin de máster por uno de nuestros alumnos con el fin de obtener información sobre el templo ibérico de La Escuera, que ella había excavado hace más de medio siglo. Los restantes artículos se organizan en dos bloques: uno dedicado a los trabajos de carácter arqueológico y metodológico, y otro centrado en la gestión y puesta en valor del patrimonio, reflejo de las dos líneas formativas del máster. Cierra este número una contribución dedicada a una de las actividades docentes más emblemáticas de nuestra titulación: el congreso de máster que se realiza cada año, una plataforma en la que los estudiantes exponen en público sus proyectos de investigación. Hemos querido recopilar, en forma de tablas organizadas por cursos académicos, la totalidad de las aportaciones presentadas en estos congresos, con la intención de dejar constancia del conjunto de autores y temáticas tratadas, y como reconocimiento a los estudiantes que a lo largo de estos años han pasado por el máster.

Confiamos que este primer número de DAMA, cuyo nombre combina un acrónimo de su título, a la vez que rememora uno de los iconos más significativos de la arqueología y el patrimonio de la provincia de Alicante, sea un buen comienzo y sirva de aliciente para nuestros futuros alumnos y alumnas. 